\title{
Correlates of inter-birth intervals: Implications of optimal birth spacing strategies in Mozambique
}

\author{
Saumya RamaRao \\ Population Council \\ John Townsend \\ Population Council \\ lan Askew \\ Population Council
}

Follow this and additional works at: https://knowledgecommons.popcouncil.org/departments_sbsr-rh

Part of the Demography, Population, and Ecology Commons, International Public Health Commons, Maternal and Child Health Commons, Public Health Education and Promotion Commons, and the Women's Health Commons

How does access to this work benefit you? Let us know!

\section{Recommended Citation}

RamaRao, Saumya, John Townsend, and lan Askew. 2006. "Correlates of inter-birth intervals: Implications of optimal birth spacing strategies in Mozambique," FRONTIERS Final Report. Washington, DC: Population Council. 


\title{
Correlates of Inter-birth Intervals: Implications of Optimal Birth Spacing Strategies in Mozambique
}

\author{
Saumya RamaRao, John Townsend \\ and Ian Askew \\ Population Council
}

March 2006

This study was funded by the U.S. AGENCY FOR INTERNATIONAL DEVELOPMENT (USAID) under the terms of Cooperative Agreement Number HRNA-00-98-00012-00 and Subproject number 8009 13016. The opinions expressed herein are those of the authors and do not necessarily reflect the views of USAID. 


\section{ACKNOWLEDGMENTS}

We wish to thank Elvira Beracochea and her colleagues at Advance Africa for a collegial collaboration; Luis Ochoa at Macro International for kindly sharing preliminary findings of the 2003 round of the Mozambique DHS; and Maureen Norton and Shawn Malarcher at USAID for technical inputs and discussions. We also thank Nathan Golon for graphical and formatting assistance. 


\section{BACKGROUND}

For years, family planning programs have advocated two year intervals between births for infant and child health and survival. There are several benefits that contribute to these outcomes including: a longer time period between births allows a mother more time to recover from pregnancy and delivery; the next pregnancy and birth are more likely to be at full gestation and growth; there is less competition between existing children for breastfeeding, food, nutrition, the mother's time, and other resources (National Research Council, 1989).

More recently, there has been a renewed interest in the effects of spacing and the optimal duration between births because new evidence suggests that three to five years may offer greater health benefits. Multivariate analyses on large data sets from a number of different settings indicate that there could be additional gains to child health by increasing the spacing between births to a minimum of three years (DaVanzo, 2004; Rutstein, 2002; Conde-Agudelo and Belizan, 2000). Furthermore, this is the first instance of empirical evidence to indicate that there are benefits to mothers as well. Previous research from Matlab, Bangladesh had suggested that there is little empirical evidence for an association between birth interval length and the risk of maternal death (Ronsmans and Campbell, 1998). However, a more recent analysis of data from Matlab, Bangladesh indicates that women with short or very long inter-pregnancy intervals are at a significantly higher risk of maternal complications (DaVanzo et al., 2004).

The Optimal Birth Spacing Initiative (OBSI) was created under the auspices of USAID to place optimal birth spacing on the global leadership priority agenda. The goal of OBSI is to institute an optimal birth spacing recommendation of Three to Five Years at the policy, programmatic and behavioral levels (http://www.rhcatalyst.org/ accessed March 23, 2005). A range of professional and technical groups are participating in this initiative including the CATALYST Consortium and Advance Africa with CATALYST acting as the secretariat for OBSI.

As part of this initiative, Advance Africa documented a pilot intervention to introduce the new spacing message in Mozambique. The FRONTIERS Program of the Population Council collaborated with Advance Africa providing technical input, and assistance in the conceptualization of intervention design and evaluation. Advance Africa is working in three provinces - Gaza, Nampula, and Zambézia_-providing technical assistance to the Provincial Directions of Health and where Advance Africa partners, Save the Children (STC) and World Vision (WV), have community-based activities. These three provinces participated in this project because of interest at the provincial and district levels in creating Optimal Birth Spacing research committees, presence of trained health workers in facilities and at the community level, and medium sized communities (populations of 3,000-5,000) where activities could take place. Each of the three provinces in located in three different geographical zones-Gaza is in the southern zone, Nampula in the northern zone, and Zambézia in the central zone. 
This paper was written to inform Advance Africa's efforts in Mozambique and has three sections. The first is a short review of correlates of birth intervals; the second presents results from analysis of Mozambique-DHS 1997 data that identifies sub-populations that may be benefit from optimal birth spacing messages; and the third discusses the implications of the findings.

\section{REVIEW OF CORRELATES OF BIRTH INTERVALS}

Birth intervals are affected by a complex range of factors, some of which are rooted in social and cultural norms, others in the reproductive histories and behaviors of individual women, utilization of reproductive health services and other background factors. A conceptual framework useful for examining birth intervals is one proposed for studying fertility (Bongaarts, 1978). This framework describes how socio-economic and cultural factors work through a set of proximate determinants to influence final fertility outcomes with four proximate determinants-marriage, contraception, lactation and induced abortion explaining most of the variation.

Empirical evidence from many different cultural settings have identified several correlates of birth intervals and these are reviewed in brief. In terms of behaviors, empirical evidence over many years and many settings indicates that lactational amenorrhea arising from breastfeeding lengthens birth intervals (Jain, Hsu, Freedman and Chang, 1970; Chen, Ahmed, Gesche, and Mosley, 1974; Jain and Bongaarts, 1981; Koenig, Phillips, Campbell and D’Souza, 1990; Mturi, 1997). Moreover, in many settings couples practice postpartum abstinence which can have additional benefits if the duration of abstinence exceeds that of postpartum amenorrhea. A recent review of birth spacing reports that a combination of postpartum amenorrhea and abstinence can result in birth spacing of two years (Setty-Venugopal, V and U.D. Upadhyay, 2002). The extent to which breastfeeding and abstinence are practiced is influenced by social and cultural norms. Birth spacing is also directly influenced by contraceptive use and induced abortion.

Another variable associated with birth interval length is the survival of the index child. The death of the index child in infancy or early childhood has been found to be associated with short subsequent intervals in settings as separate as Bangladesh and Tanzania (Chakraborty, Sharmin and Islam, 1996; Mturi, 1997). This occurs for several reasons. Sometimes, parents consciously plan a new pregnancy to replace a lost child. There are unintentional reasons for short spacing too - the death of a child cuts short nursing durations which results in earlier resumption of menses and ovulation.

Other socio-economic factors such as the mother's place of residence, education and work have also been correlated with birth spacing although the mechanisms by which these background variables influence birth spacing is less clear. In some settings, maternal education is associated with shorter spacing; in Korea, for example, one study reported that better educated women had shorter second birth intervals than those less educated (Bumpass, Rindfuss, and Palmore, 1986). However, in 38 of 51 countries with 
DHS data, women with no education were more likely than educated women to have shorter intervals (Setty-Venugopal, V and U.D. Upadhyay, 2002). The reason for such diversity is uncertain. It can be conjectured that better educated women wish to compress childbearing into fewer years and participate in non-childbearing activities and hence have shorter spacing.

Rural residence is also associated with short intervals in 51 of 55 countries with DHS data (Setty-Venugopal, V and U.D. Upadhyay, 2002). For example, in Tanzania, urban women were 18 percent less likely to have conceived and closed an interval than rural women (Mturi, 1997). The effect of maternal employment on spacing is less clear-in some settings it appears to be associated with shorter spacing. The nature of work is perhaps more important - employment in the formal and modern sector has been found to be related to longer spacing (Mturi 1997; Setty-Venugopal, V and U.D. Upadhyay, 2002).

Maternal age at the birth of the index child is associated with birth intervals. In general, older mothers tend to have longer subsequent intervals (Chakraborty, Sharmin and Islam, 1996; Mturi, 1997; Setty-Venugopal, V and U.D. Upadhyay, 2002). This could be due to two reasons-older women are later in their childbearing process and are likely to have achieved their desired family size and hence likely to have long subsequent spacing; they are also likely to be less fertile leading to long spacing.

Less is known about how biological and genetic factors effect birth intervals. For example, the women vary in their capacity to conceive or carry a pregnancy to term. The mother's health and nutritional status at the start of a pregnancy affects the outcome of the pregnancy, her ability to breastfeed, and the health of the baby especially early in infancy. There can be other household and familial influences that can have unobserved but direct effects on birth spacing. For example, the extent to which couples make joint reproductive decisions or use available household resources to access services and practice healthy behaviors may influence birth spacing.

Program models add to this information and framework by looking at ways in which services can influence some behaviors and outcomes. The challenge for the OBSI initiative will be to link social, cultural and behavioral determinants with programs and services to achieve best health impacts (Townsend, 2003).

\section{ANALYSIS AND FINDINGS}

\section{Data}

We present data from the 1997 DHS conducted in Mozambique. ${ }^{1}$ The DHS collected information from women in the reproductive ages (15-49). Pregnancy histories were

\footnotetext{
${ }^{1}$ A second round of the DHS was conducted in 2003/04. At the time of this analysis, only the preliminary report was available. Published tables in the preliminary report indicate that the total fertility rate and the length of the birth interval was similar between the two DHSs leading us to believe that analysis based on the 1997 survey will still be useful programmatically.
} 
collected from all respondents; additional information was collected from those who had a live birth in the three years prior to the survey. ${ }^{2}$ Information collected covered the antenatal, delivery and postpartum periods and included: desired timing of the pregnancy, antenatal care, delivery care, return of menstruation, duration of postpartum abstinence, and breastfeeding. ${ }^{3}$

There are various ways of measuring birth intervals: from pregnancy to pregnancy or inter-pregnancy intervals, between birth, and birth-to-conception intervals. The type of interval used depends on the issue being studied. We calculated inter-birth intervals, or the duration between two succeeding births, using the data from the pregnancy history.

We omitted two types of intervals from our analysis: the interval between sexual debut and first birth because it is not an inter-birth interval, and the open interval between the last birth and the interview due to the problem of censoring. Excluding the interval between sexual debut and first birth will also exclude women who have given birth only once-typically, this will include women who have difficulties in carrying a pregnancy to term and delivering and those who are early in their reproductive careers and are yet prepared to give birth a second time. ${ }^{4}$ By focusing only on inter-birth intervals or closed intervals, we limit our understanding of what makes open intervals long, as open intervals tend to be longer than closed intervals. Further, it ignores any pregnancies that did not come to term within the period and cannot thus provide complete information on the links to maternal health.

Nevertheless, we can still learn a lot from a study of inter-birth intervals to inform optimal birth spacing strategies. The inter-birth interval is the crucial variable of interest in this paper. It is categorized as follows: those that are less than 3 years, between 3 and 5 years, and over 5 years.

We also present information on a range of other factors that may determine or be determined by inter-birth intervals. Some of these have been identified in the literature and include socio-economic background variables (age, education, employment status), reproductive history and attitudes (parity, reproductive intentions), and behavioral variables (duration of breastfeeding, abstinence, and use of contraception).

\section{Analysis}

In 1997, the average birth interval nationally was over three years (3.63) and the 2003 preliminary DHS report indicates that there has been little change in the median birth interval between the two survey periods. ${ }^{5}$ Figure 1 shows that the three Advance Africa

\footnotetext{
${ }^{2}$ Information was collected for a maximum of two live births in the period.

${ }^{3}$ Other important issues covered included vaccination for children and care of childhood illnesses.

${ }^{4}$ In Mozambique, 21.5 percent of 15-49 year old women had not given birth, the greater majority being younger women. 70 percent of 15-19 year olds and 21 percent of 20-24 year olds had not given birth. Among the 15-19 year olds who had given birth, 25 percent had given birth once and 6 percent twice (Mozambique 1997 DHS).

${ }^{5}$ In 2003, the median interval between two successive live births is reported to be 34.4 months or 2.86 years; in 1997, the median was 34.6 or 2.88 years.
} 
provinces clustered around the national average with slight variation-ranging from 3.24 years in Nampula to 3.77 years in Gaza.

\section{Figure 1: Average birth interval}

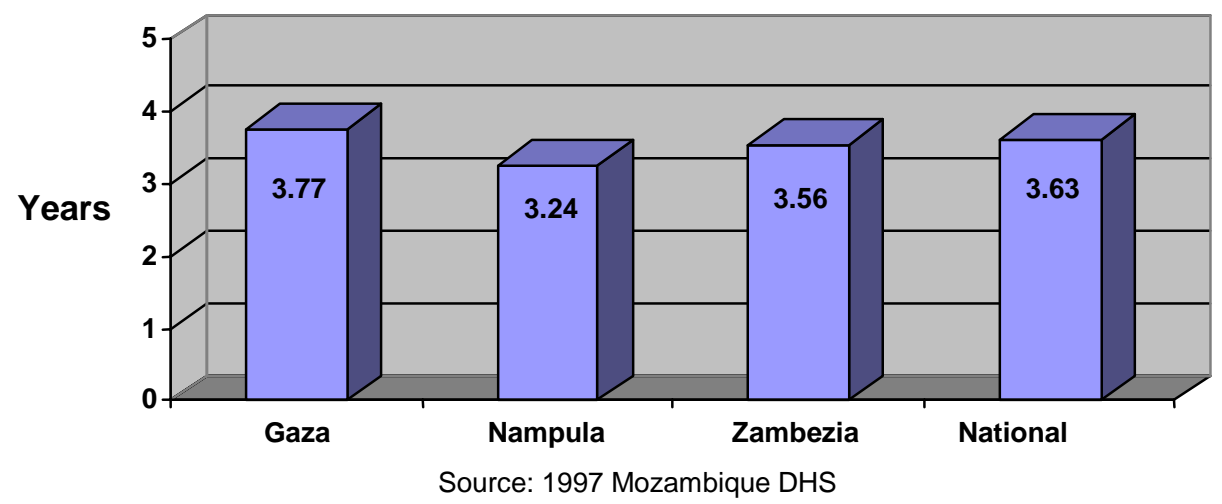

The mean suggests that most birth intervals are already sufficiently long in this setting. However, an examination of the birth interval distribution by duration categories $(<3$ years, $3-5$ years, and $>5$ years) reveals that there is a sub-group of women who have intervals shorter than the new norm of 3 years. About half of the intervals are less than three years as seen in Figure 2.

\section{Figure 2: Distribution of birth intervals by duration}

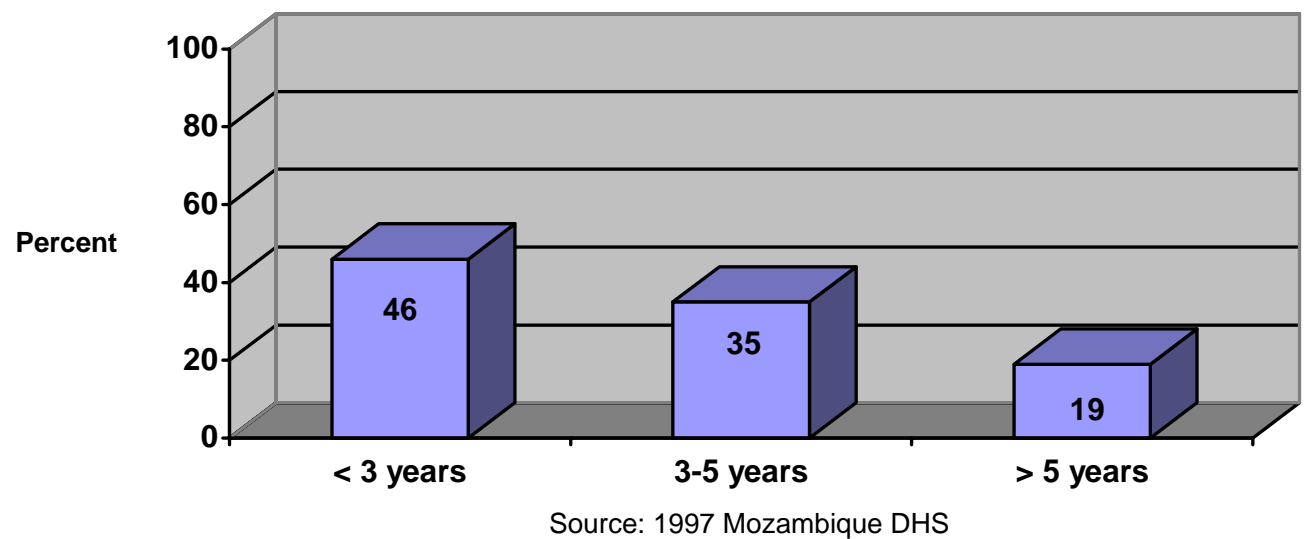

There are some urban-rural differentials with rural women less likely than urban women to have intervals over five years. Interestingly, they are also more likely to already be having intervals of between 3 and 5 years (35\% of rural women versus $31 \%$ of urban women-Figure 3). 


\section{Figure 3: Urban and rural differentials in birth spacing}

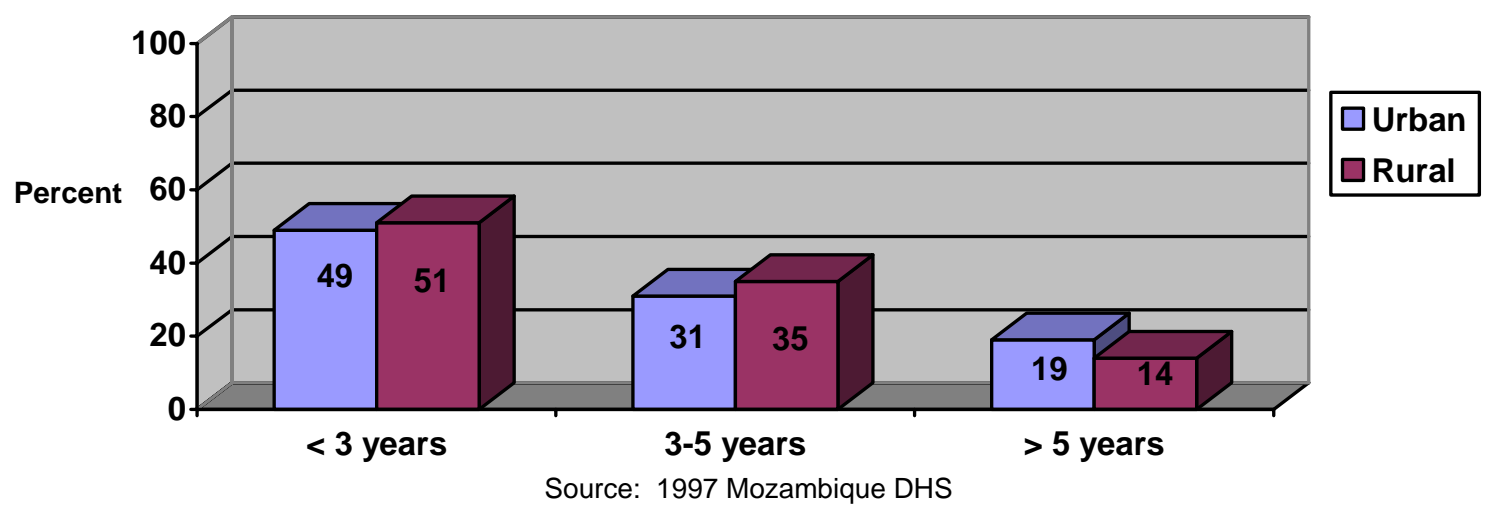

Since births occurring within two years are riskier, we describe those mothers who had such very short intervals. There is not a considerable difference in behavior among 15-19 year olds and those in their 20s; differences begin to appear in those over 30 and 40 years of age as can be seen in Figure 4. An alternate way is to compare median intervals across age groups, which reveals the same pattern - the shortest median interval does occur among younger mothers than older but there is not a sizeable difference between those under 19 and those in their 20s; 15-19 year old mothers have the shortest interval of 28.9 months while those 20-29 have slightly longer intervals of 32.7 months. Only those who are thirty and older have intervals longer than three years—36.3 months among 30-39 year olds and 41.7 months among those forty and over.

\section{Figure 4: Percent distributions of short* birth intervals by maternal age}

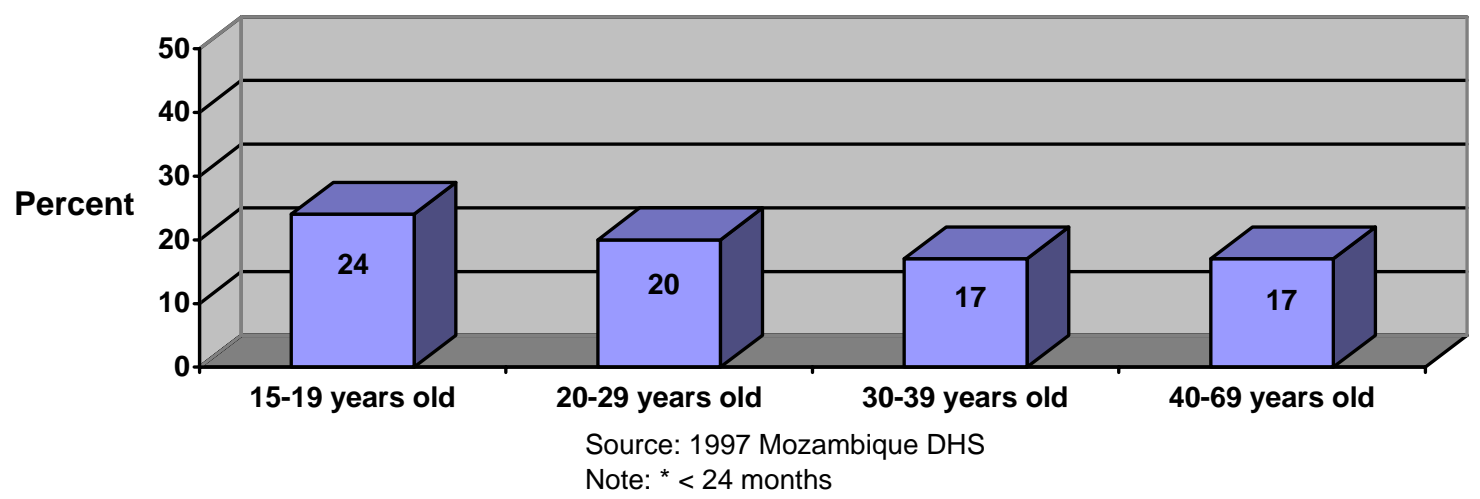

As expected, parity is correlated with intervals of less than 2 years, and is apparent at higher parities; less than a fifth of short intervals occurred to women who had between 2 and 6 children compared to over a quarter among those with seven or more children 
(Figure 5). However, from a program perspective, there is no easy intervention point as there is little variation in median interval length (between 33 and 35 months across different parities). A more promising avenue for intervention is feasible that is linked to child survival. We found an expected association between survival of the previous child and very short birth interval- a third of births occur within 24 months when the previous child does not survive, compared to fifteen percent when it does.

\section{Figure 5: Percent distribution of short* intervals by parity}

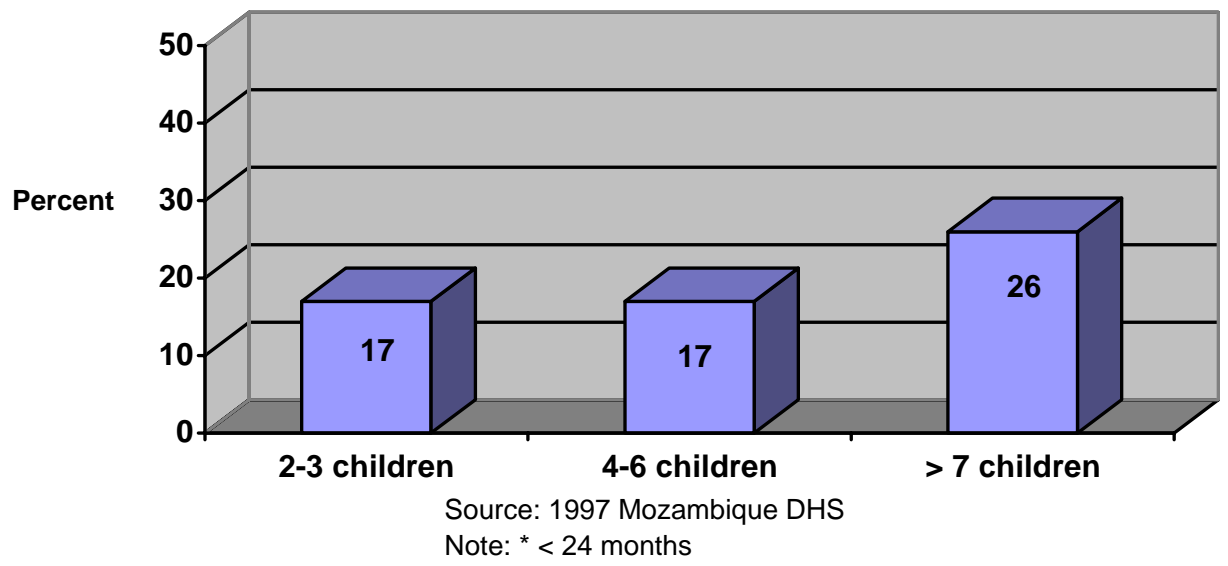

\section{Socio-economic characteristics}

We also examined which women were more likely to have short birth intervals of three years or under. In general, younger women were more likely to have an interval less than three years than those older; nationally, three-quarters of 15-19 women were likely to have a short preceding interval while lower proportions of older women have such short intervals (see Figure 6). A similar pattern was observed in all three provinces. ${ }^{6}$ This pattern makes intuitive sense because younger women are more likely to have children for a variety of reasons such as greater fecundity and being early on in the family building process.

\footnotetext{
${ }^{6}$ We do not present percentages by province because of small number of cases in some cells.
} 


\section{Figure 6: Percent distribution of short* birth intervals by maternal age}

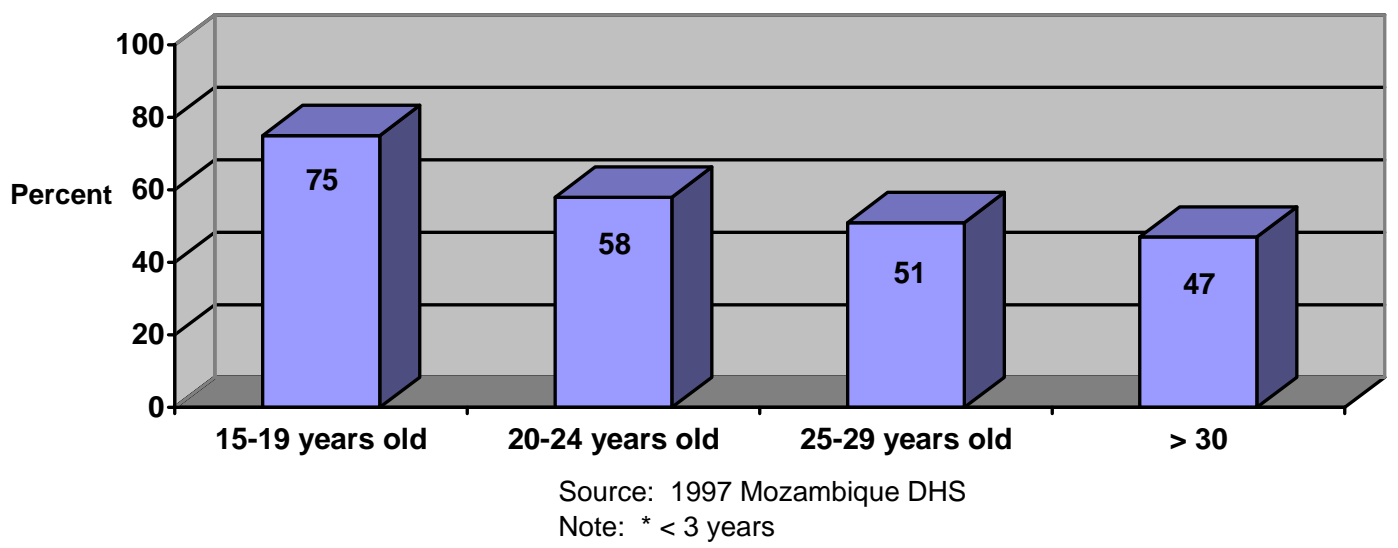

Literacy and schooling levels are low in Mozambique; two-thirds of girls and a third of boys aged 15-19 are illiterate. ${ }^{7}$ Given this context, we expected to see some differences in inter-birth intervals by ability to read. At the national level, the data indicate that women who read easily are the least likely to have short intervals (Figure 7). There are provincial level differences. In Gaza, literacy does not seem to be associated with birth interval length unlike the other two provinces. In Nampula, those who can read with difficulty are the most likely to have intervals less than three years. Interestingly, in Zambezia, short intervals occur to those who are the most literate. Similar associations of educational achievement and short intervals have been observed in other settings as well; for example, in Korea, the most educated women were more likely than the least to have a birth earlier (Bumpass, Rindfuss and Palmore, 1986). This could be due to better educated women wishing to compress childbearing into a shorter period of time.

\section{Figure 7: Percent distribution of short* birth intervals by maternal literacy}

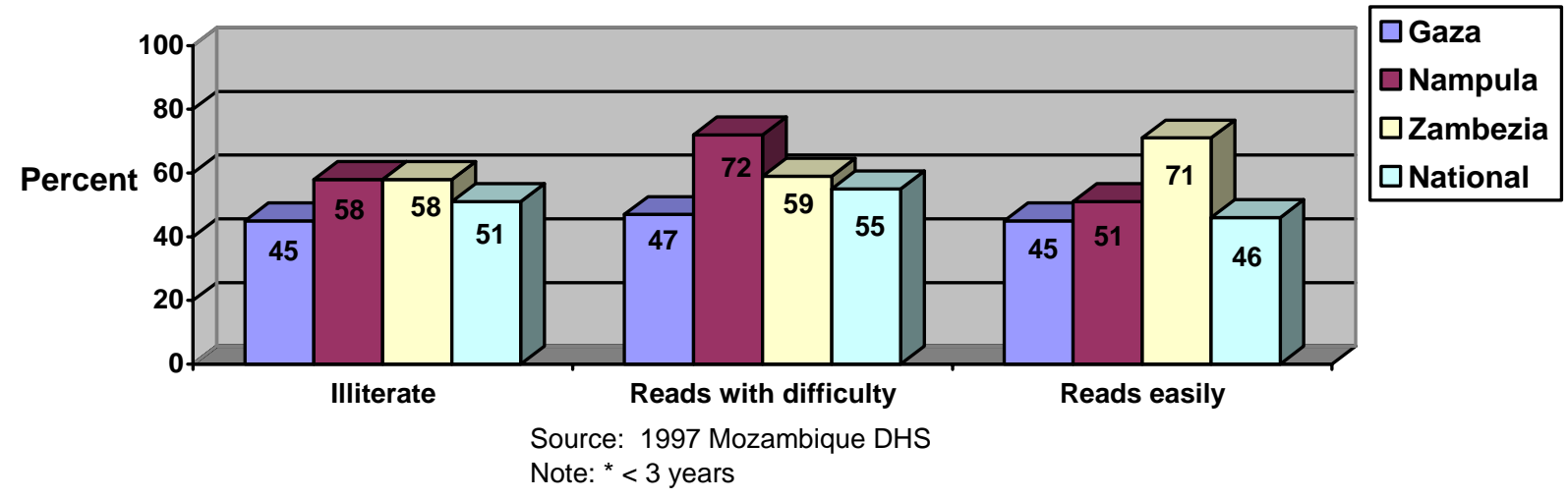

\footnotetext{
${ }^{7}$ Population Reference Bureau. http://www.prb.org/datafind/prjprbdata/wcprbdata5.asp?DW=DR\&SL=\&SA=1 Accessed April 13, 2005.
} 
Because male educational rates are higher than women's, we examined if there were different patterns in inter-birth intervals by levels of partner's education. We found similar results to female educational rates. At the country level, 50 percent of intervals less than three years occurred among women whose partners have no education compared to 52 percent among those with partners with at least a primary education.

In terms of all background socio-economic variables, whether a woman is currently working shows the most correlation with the length of her previous inter-birth interval. At the national level, those who are working are significantly less likely to have intervals shorter than three years than those working; nationally, 49 percent among those working versus 53 percent among those who are not (Figure 8). At the provincial level, these patterns sustain, albeit without statistical significance. These findings are consistent with empirical findings reported from different cultural settings where correlations between women's work status, contraceptive use and fertility have been observed (for example, Becker et al., 1993; Wong, 2000). This could be due to working women having better access to knowledge on fertility regulation thereby contributing to a reduction in pregnancies and hence lengthening inter-birth intervals.

In summary, while we see statistically significant differences across some socioeconomic groups, these cannot be translated into policy or program relevant activities due to the relatively small size of the potential change.

\section{Figure 8: Percent distribution of short* birth intervals by maternal work status}

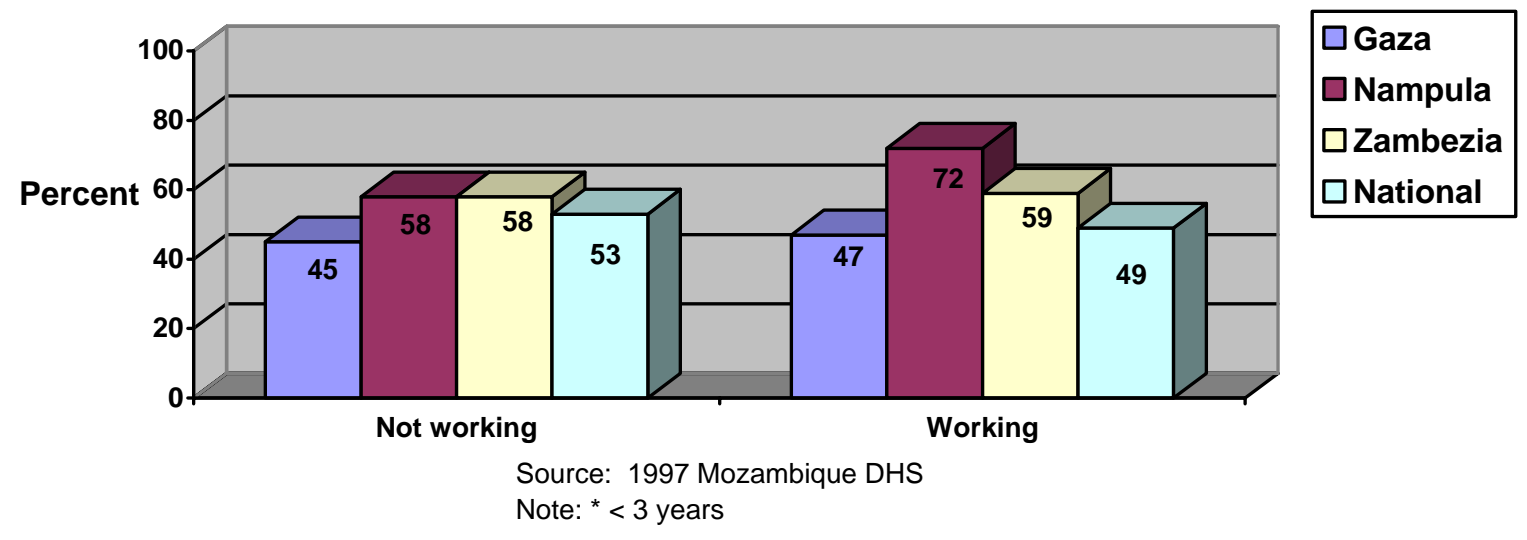

Reproductive aspirations and history

In addition to these contextual factors, there are others more proximate that could influence the length of an inter-birth interval. These include the type and nature of a woman's relationship, whether her partner resides with her, her reproductive aspirations, her reproductive history, and her reproductive behavior. Not surprisingly, women who are currently married (or in union) or are co-residing with their husband (or partner) are more likely than others to have short intervals given the greater exposure to sexual activity and pregnancy. For example, at the national level, 52 percent of short intervals 
occurred among women who are currently married or in union compared to 45 percent among other women; similarly 58 percent occurred among women who co-resided with their husbands (or partners) compared to 67 percent of non co-residents. ${ }^{8}$

Birth intervals are closely linked with the number of children a woman has. There are two ways in which parity is linked to interval length. The literature has often suggested that those who have suffered a pregnancy or child loss are more likely to replace that pregnancy/child and hence the interval between births is short. A second explanation is related to the fecundity factors - women who conceive easily and quickly are also those who are more likely to have more children. Due to these different effects, the relationship between parity and birth interval is often U-shaped; shorter intervals for those who have few children or many children and longer intervals for those who have a moderate number of children. This general pattern holds across Gaza, Nampula and Zambezia (Figure 9). Women who have few currently living children (none or one) or over five children more likely to have short intervals than those who have between two and four children. ${ }^{9}$ For example, in Nampula this is a statistically significant relationship - 79 percent of those with few children had short intervals, as did 53 percent of those with two to four children, and 57 percent of those who had five or more. ${ }^{10}$

Figure 9: Percent distribution of short* birth intervals by number of living children

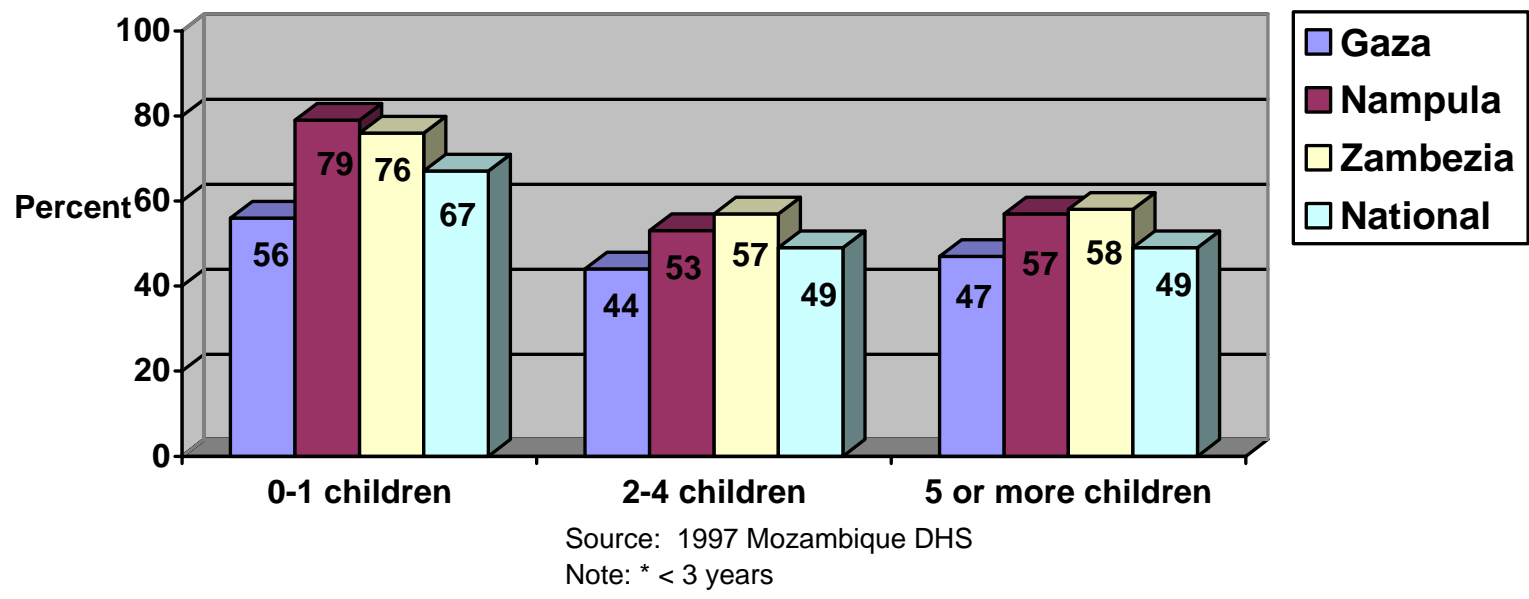

The data also indicate that interval length is also determined by whether the last child was an unplanned pregnancy in terms of its timing or wantedness. Figure 10 presents birth intervals by the wantedness of the previous pregnancy. Nationally, women who reported that their last child had been mistimed were more likely to have short intervals (65\%)

\footnotetext{
${ }^{8}$ We do not present provincial level estimates due to small cell sizes.

${ }^{9}$ The focus on current living children is to reflect that some women may have experienced infant or child death.

${ }^{10}$ In Gaza, the corresponding figures were 56\%, 44\% and 47\%; in Zambezia 76\%, 57\% and 58\%. Nationally, $67 \%$ with none or one living child were likely to have short inter-birth intervals compared to $49 \%$ of others.
} 
compared to 43 percent who wanted their child then and 41 percent who wanted no more. Wantedness of a pregnancy is significantly correlated with birth interval length, despite the possibility that some unwanted pregnancies could be post-birth rationalized as being wanted.

\section{Figure 10: Percent distribution of short* birth spacing by reproduction intention}

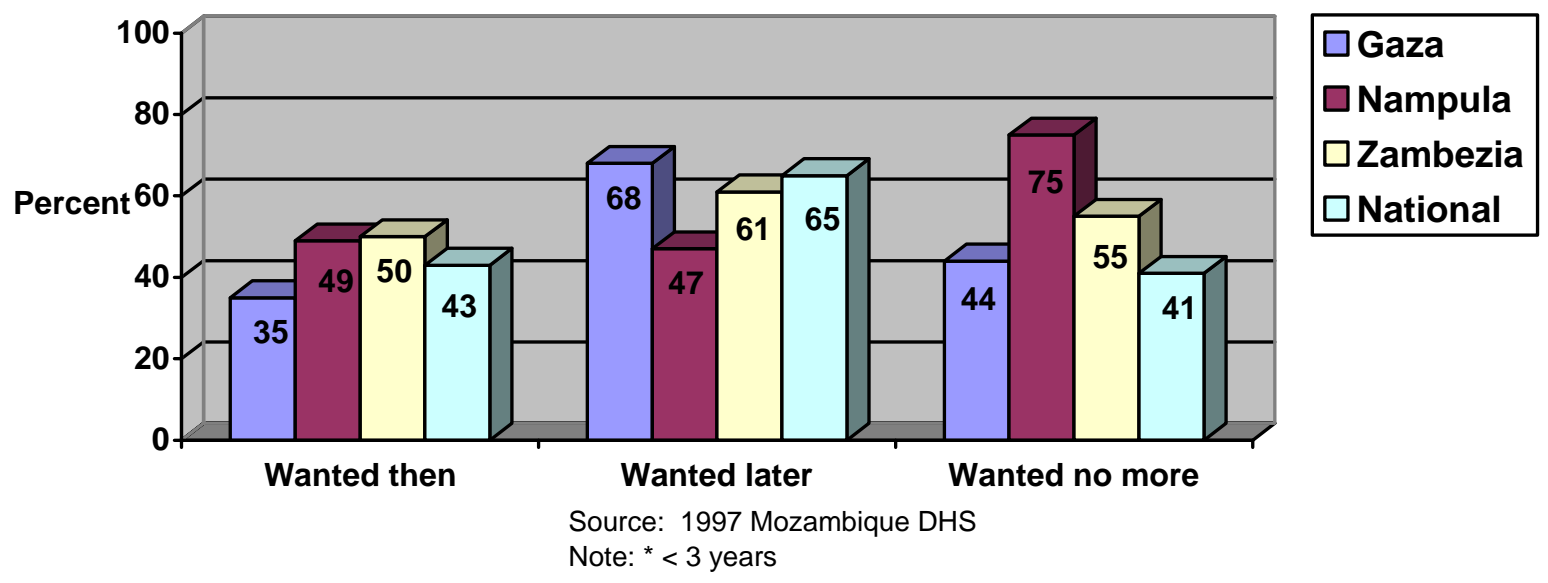

It has been observed that in cultural settings with son preference, the sex of the previous child can determine the subsequent interval length; the birth of a girl is typically followed by a shorter interval than if a boy had been born. In this setting, the sex of the previous child does not seem to influence the length of the interval; for example, short intervals follow a boy's birth in 51 percent of the cases and 50 percent of the cases when a girl is born.

Social and reproductive behaviors

Breastfeeding, abstinence and the use of contraception are some examples of social and reproductive behaviors that can influence inter-birth length. For example, nursingespecially exclusive breastfeeding — can extend the period of post-partum amenorrhoea, thereby lengthening the interval between births. Abstaining or using contraception work more directly by postponing the occurrence of the next pregnancy. The combination of these behaviors affects the resulting birth interval. We study each of these below. 
Figure 11: Median durations of breastfeeding, post-partum abstinence and amenorrhea

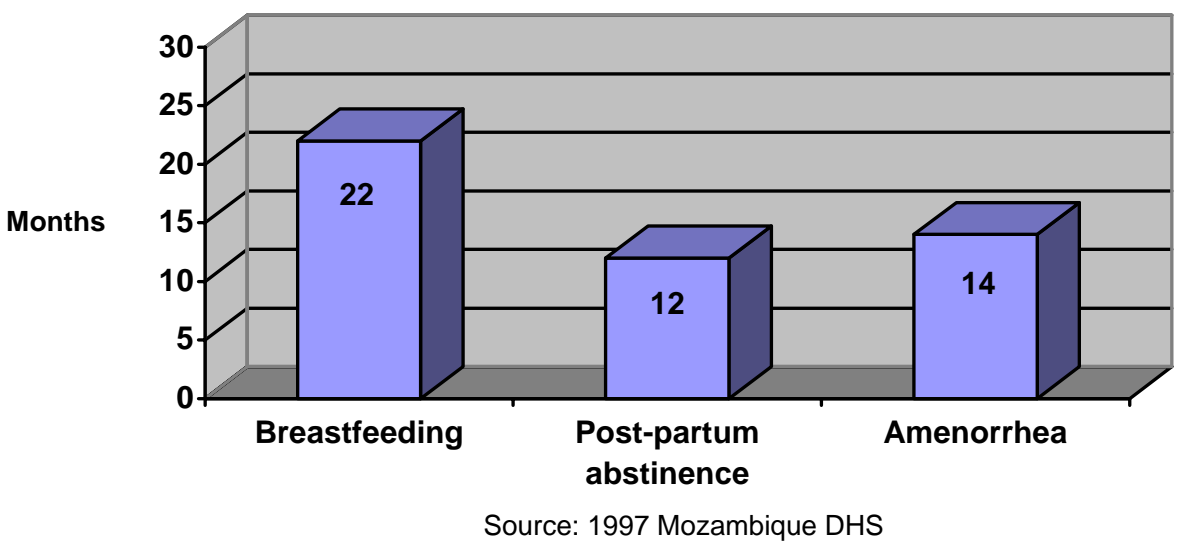

Women nurse and abstain for fairly long periods (Figure 11). The median duration of breastfeeding is 22 months and 13.7 months for post-partum amenorrohoea; post-partum abstinence is also fairly long at little less than a year or 11.6 months (Gaspar et al., 1998).

Breastfeeding for up to six months reduces short inter-birth intervals; for example, 48 percent of women who did not nurse are likely to have intervals less than three years compared to 39 percent of those who had nursed between one and six months. However, nursing beyond six months does not increase the interval further; 46 percent of women who nursed for 7-12 months had short intervals as did 51 percent of those who nursed for 12 to 24 months and 56 percent of those who nursed over two years.

Contraceptive use is also low in this setting. In 1997, the contraceptive prevalence rate was 6 percent, comprising of both modern and traditional method use (Gaspar et al., 1998). All the three study provinces had rates lower than the national estimates; for example, modern method use among married women in Gaza was 1.8 percent, in Nampula 2 percent, and in Zambezia 4.7 percent. $^{11}$

\section{Service utilization}

We examined some measures of service utilization with a focus on maternal and child health services as these can be points for disseminating information on birth spacing. Women tend to use antenatal services - over three-quarters of women had used antenatal care. Their first antenatal visit occurs in the second trimester (median months into pregnancy is 5) and over the course of the pregnancy they make a median of 3.4 visits. There is a wide variance in the antenatal service use across the three provinces, ranging from a low of 51 percent in Zambezia, 70 percent in Nampula to a high of 92 percent in Gaza.

\footnotetext{
${ }^{11}$ By 2003, contraceptive prevalence had increased in all three provinces—by 13 points in Gaza, 8 points in Nampula and 6 points in Zambezia.
} 
Despite the fairly high level of antenatal care use, over half of deliveries (55\%) occur at home, and in 45 percent of the cases are attended by family members and others. Once again there is a wide dispersion across the provinces and they mimic the pattern of antenatal care seen above. In Zambezia, 76 percent of deliveries occur at home and 70 percent are attended by family members and others (Nampula: 71\% home deliveries and 69\% attended by family members; Gaza: 30\% home deliveries; $19 \%$ attended by family members).

We examined vaccination coverage to assess use of child health services. The provincial patterns in use are similar to those noted in maternal services. While the national estimate of complete immunization is 47 percent, it varies from a low of 23 percent in Zambezia, 34 percent in Nampula and 63 percent in Gaza. It is clear that there are geographical differences and these may be related to both issues of access or low demand.

\section{FINDINGS AND PROGRAMMATIC OPTIONS}

Mozambique is a country with high infant, child and maternal mortality. Recent data indicates that infant mortality is 127 per 1,000 live-births and child mortality is 215 per 1,000 children (www.prb.org; accessed April 23, 2005). Maternal mortality is equally high at 980 per 100,000 live-births. This poor reproductive health situation provides a rationale for focusing on the mother-baby dyad for better health outcomes for both. OBSI is a mechanism that can contribute to that goal.

However, the context in Mozambique is one of long birth intervals and the challenge will be to find the best mechanism to promote even longer birth spacing. In this setting, OBSI can be one of several interventions undertaken to promote the health and survival of women, infants and children. It will also be important to assess the extent to which OBSI will have an independent impact. We next lay out some ideas and options for policy makers, service providers and communities to consider.

What should policy makers consider?

- Policy makers need to consider the potential for lengthening birth intervals in Mozambique where the median birth interval is close to 3 years (2.88 years). Data from other African countries suggests that even in situations when women wish to increase spacing it is by no more than six months (Rafalimanana and Westoff, 2001).

- Policy makers also need to clearly articulate what the OBSI strategy will achieve. In the post-Cairo world with a focus on client-centeredness, it is important for policy makers to explicitly articulate the benefits of OBSI for maternal and child health. For many years, birth spacing has been largely studied and promoted for its demographic, rather than health, effects because longer spacing can lower birth rates. 
In terms of interventions, it will be programmatically relevant to focus on very young mothers (under 19), those with very short intervals (less than 24 months), and those who are most at risk of short breastfeeding without contraception.

- Postponing the first birth could be a promising intervention point. The median age at first birth in Mozambique is 19. Thirty percent of girls between the ages of 15-19 are already mothers and there is potential to reduce early childbearing by focusing on this segment of the youth population.

- Promoting at least two years between births among very young mothers is another potential intervention. While little can be done to reduce the risk of a first time pregnancy, the risk of repeated childbearing in young ages can be reduced. About a quarter of 15-19 year old girls have a birth within 24 months of the previous birth, compared to a fifth (19.7\%) of those 20-29.

What should program managers, supervisors and providers consider?

Policy changes should also be accompanied by changes ranging from reorganization of services, development of new guidelines and protocols for service delivery, and new information and communication (IEC) messages, to facilitative supervision to support the new initiative.

At the operational level:

- Supervisors will have to help providers create messages about the new birth spacing norm that do not confuse beneficiaries with the old message of two years. This message will also have to include information that contraceptives can be used safely for longer periods. Second, supervisors will have to help providers imbibe the spirit of client-centeredness that respects women's preferences for the timing and number of pregnancies without "motivating" them to space for longer periods, if they do not choose to do so. Third, they will have to provide appropriate supervision such that providers are able to carry out the newly organized services and service messages.

- Providers need to elucidate mechanisms to achieve optimum birth spacing. Currently contraceptive use is low in Mozambique but breastfeeding durations are long. They can emphasize social and cultural practices that promote breastfeeding for appropriate durations. They can also suggest the use of contraceptives to achieve the client's desired spacing.

\section{What should communities consider?}

Optimal birth spacing can build on existing social and cultural norms. Community involvement and participation can enhance community ownership, build support and legitimacy. Many community and civic groups exist; for example, mothers' groups, civic groups addressing literacy, empowerment, or nutrition and child development, or 
women's self-employment groups such as micro-credit and/or micro-enterprise groups that can voice community concerns and opinions.

Issues that communities can contribute to:

- Discussion on issues surrounding family size, the pros and cons of spacing, the best mechanisms to achieve desired family formation, and the associated costs.

- Discussion on women's roles in society including home-making, childbearing, caregiving, and non-reproductive roles outside the home, and the extent to which longer spacing can have an impact on their reproductive lives.

\section{Additional Research Needs}

A wider implementation of the OBSI strategy in Mozambique will require a better understanding of the national cultural and social context. Listed below are a few key areas that will require additional research.

- A better understanding of women's preferred or ideal birth spacing. Interventions promoting specific spacing messages will be successful the closer they are to women's own preferences and desires. Otherwise, as observed with other health messages, such promotion will have limited impact. Exhortations to follow specific guidelines that may be contrary to women's desires and wishes will not result in optimal birth spacing behaviors.

- Projections of the estimated impact of birth spacing on maternal and child health. For example, analysis conducted by Rafalimanana and Westoff (2001) of DHS data from 20 sub-Saharan countries indicated that if women realized their desired birth-spacing, it could lead to modest decreases in child mortality and little change in child malnutrition. Similar simulation exercises on the most current Mozambique data will estimate the extent to which OBSI objectives will be feasible. Should the estimated size of the impact be modest, it will be necessary to rethink the strategy; further, it will also be important to weigh the OBSI message versus women's own wishes for spacing and achieving reproductive goals.

- Better understanding of the changing roles of gender norms and women's roles in society. Economic and social development alters women's roles and the options they have. In many countries, social development has resulted in higher education and labor force participation of women; as well as a later age at marriage, later age at childbearing and earlier completion of childbearing resulting in shorter birth spacing. Thus these expected changes in women's roles and participation in civic and economic activities may move in a contradictory direction to longer birth spacing. Hence, birth spacing messages should be cognizant and sensitive to all aspects of women's lives, and the extent it can limit non-reproductive roles. 


\section{REFERENCES}

Becker, S., D.H. Peters, R.H. Gray, C. Gultiano, and R.E. Black. 1993. “The determinants of use of maternal and child health services in Metro Cebu, the Philippines.” Health Transition Review, Vol. 3(1): 77-89.

Bongaarts, John. 1978. "A framework for analyzing the proximate determinants of fertility.” Population and Development Review, Vol. 4(1): 105-132.

Bumpass, Larry L, Ronald R. Rindfuss, and James A. Palmore. 1986. "Determinants of Korean birth intervals: The confrontation of theory and data." Population Studies, Vol. 40(3): 403-423.

Chakraborty, Nitai, Sayema Sharmin, and M. Ataharul Islam. 1996. "Differential pattern of birth intervals in Bangladesh.” Asia-Pacific Population Journal, Vol. 11(4): 73-86.

Chen, Lincoln.C., Shamsa Ahmed, Melita Gesche, and W.Henry Mosley. 1974. “A prospective study of birth interval dynamics in rural Bangladesh.” Population Studies, Vol. 28(2): 277-297.

Conde-Agudelo, A and J.M. Belizan. 2000. "Maternal morbidity and mortality associated with interpregnancy interval: Cross sectional study.” British Medical Journal (Clinical Research Ed.), Vol. 321(7271): 1255-1259.

DaVanzo, Julie, Abdur Razzaque, Mizanur Rahman, and Lauren Hale, with Kapil Ahmed, Mehrab Ali Khan, Golam Mostafa, and Kaniz Gausia. 2004. "The Effects of Birth Spacing on Infant and Child Mortality, Pregnancy Outcomes, and Maternal Morbidity and Mortality in Matlab, Bangladesh.” Rand Working Paper, WR-198. Santa Monica, California: Rand.

Gaspar, Manuel da Costa, Humberto A. Cossa, Clara Rebeiro dos Santos, Rosa Marlene Manjate and Juan Schoemaker. 1998. Mozambique DHS 1997. Calverton, Maryland, USA : Instituto Nacional de Estastica and Macro International, Inc.

Jain, Anrudh K., T.C. Hsu, Ronald Freedman, and M.C. Chang. 1970. "Demographic aspects of lactation and postpartum amenorrhea.” Demography, Vol. 7(2): 255-270.

Jain, Anrudh K and John Bongaarts. 1981. "Breastfeeding: Patterns, correlates and fertility effects.” Studies in Family Planning, Vol. 12(3): 79-99.

Koenig, Michael, James F. Phillips, Oona M. Campbell, and Stan D’Souza. 1990. "Birth intervals and childhood mortality in rural Bangladesh.” Demography, Vol. 27(2): 251265. 
Mturi, Akim J. 1997. “The determinants of birth intervals among non-contracepting Tanzanian women.” African Population Studies, Vol. 12(2). Accessed at http://bioline.utsc.utoronto.ca/archive/00000518/ on September 26, 2005.

National Research Council. Committee on Population. 1989. Contraception and Reproduction: Health Consequences for Women and Children in the Developing World. Washington, DC: National Academy Press.

Rafalimanana, Hantamalala and Charles F. Westoff. 2001. "Gap between Preferred and Actual Birth Intervals in Sub-Saharan Africa: Implications for Fertility and Child Health.” DHS Analytical Studies No. 2. Calverton, Maryland: ORC Macro.

Ronsmans, Carine and Oona Campbell. 1998. "Short birth intervals don't kill women: Evidence from Matlab, Bangladesh.” Studies in Family Planning, Vol 29(3): 282-290.

Rutstein, Shea. 2002. "Effect of birth intervals on mortality and health: Multivariate cross-country analyses." Power Point Presentation made at the Champions Meeting on Birth Spacing organized by the CATALYST Consortium, Washington DC, 31 January 2002.

Setty-Venugopal, V and U.D. Upadhyay. 2002. Birth Spacing: Three to Five Saves Lives. Population Reports, Series L, No. 13. Baltimore: Johns Hopkins Bloomberg School of Public Health, Population Information Program.

Townsend, John. 2003. "Evidence-based Programming for Birth Spacing.” PowerPoint presentation made at the Fourth Champions Meeting on Optimal Birth Spacing organized by the CATALYST Consortium and USAID, Washington, DC., 2 September 2003.

Wong, Emelita. 2000. Women's work, fertility level, and contraceptive use: A synthesis of results from Bolivia, the Philippines, and Zimbabwe. Report. The Policy Project: Washington, DC. http://www.policyproject.com/pubs/commissionedresearch/fhi.pdf (accessed September 13, 2005). 